\title{
Behavioral Analysis of a Lithium Ion Battery (Li-Ion), a Nickel Metal Hydride Battery (Ni-MH) and a Supercapacitor in an Isolated Photovoltaic Solar System
}

\author{
Laura Milena Cruz Moreno*, Diego Fabián Martín Rincón, Johann Alexander Hernández \\ Electric Engineering, Distrital Francisco José de Caldas University, Bogotá, Colombia \\ Email: ^lmcruzm@correo.udistrital.edu.co
}

How to cite this paper: Moreno, L.M.C., Rincón, D.F.M. and Hernández, J.A. (2017) Behavioral Analysis of a Lithium Ion Battery (Li-Ion), a Nickel Metal Hydride Battery $(\mathrm{Ni}-\mathrm{MH})$ and a Supercapacitor in an Isolated Photovoltaic Solar System. Energy and Power Engineering, 9, 293-308.

https://doi.org/10.4236/epe.2017.94020

Received: January 6, 2017

Accepted: April 27, 2017

Published: April 30, 2017

Copyright $\odot 2017$ by authors and Scientific Research Publishing Inc. This work is licensed under the Creative Commons Attribution International License (CC BY 4.0).

http://creativecommons.org/licenses/by/4.0/

\begin{abstract}
This paper presents experimental research about the behavior of different storage devices such as Li-ion, Ni-MH batteries and supercapacitors when charged by a solar photovoltaic system. Photovoltaic systems work as a variable current source, depending on the solar irradiance. These devices present a different profile charge compared to a constant and controlled charge generated by a traditional charger. For this work, several charging and discharging cycles of batteries and supercapacitors under the same environmental conditions were carried out in order to observe the different characteristics of each technology, and some harmful effects on the storage devices operation such as the memory effect and partial discharges involved in the proper functioning of the solar photovoltaic system.
\end{abstract}

\section{Keywords}

Supercapacitors, Memory Effect, Discharge, Accumulators, Overvoltage

\section{Introduction}

In recent decades solar photovoltaic systems have been booming due to the reduction costs of solar panels, and the development of complementary devices for this technology such as regulators and inverters, which increasingly have better technical features. But the reason why solar photovoltaic systems have not been implemented massively is the cost of storage devices which usually are the most expensive part of the system and even more expensive when dealing with acquiring an accumulator that is friendly with the environment.

The most commonly used accumulator in solar photovoltaic systems are the 
lead-acid and nickel cadmium ones. These have a high energy density and efficiency, but their reuse is not sustainable, as the fuse of these batteries for giving them a second use produce highly toxic gases that substantially affect human health. Other types of batteries present cycling processes more environmentally friendly, in which the metal hydrides, nickel and steel is separated for later use in scientific purposes, nickelled or even used to manufacture new batteries [1]. However, all batteries cannot be reused in their completely as Lithium Ion batteries. Although it is possible to extract lithium, a second use for this element is still undefined. There are several kinds of batteries available in the market. These batteries have advantageous characteristics for their implementation in solar photovoltaic systems because they are lighter, have smaller self-discharged, and have a high energy density. Despite, technology storage battery is conveyed through an electrochemical process, which produces a reduced battery life-time, requiring constant maintenance, and harmful effects to make charging and discharging in an inappropriately way. But these disadvantages would be insignificant when referring to a technology such as ultracapacitors and superconducting coils. Ultracapacitors technology enables the charging/discharging in several seconds without requirement of maintenance in addition to this in recent research [2] about double layer capacitors showed that it is possible to enhance the energy density of the ultracaps by using different materials in the electrodes. For all that, nowadays the technology is still expensive and the devices are much larger than the battery with the same capacity. On the other side, superconducting coils are able to inject or absorb large amounts of energy in very short periods of time, being used to solve quality grid problems. The different storage devices characteristic raise the question of what storage system is more appropriate for an isolated solar photovoltaic system.

There are several kinds of batteries available in the market. For example, batteries made with less toxic chemicals, such as the aforementioned nickel-metal hydride (Ni-MH), Lithium-Ion (Li-ion) and subsequent alloys batteries such as nickel iron polymers and lithium, among others. These batteries have advantageous characteristics for their implementation in solar photovoltaic systems because they are lighter, have smaller self-discharge, and have a high energy density. A battery-based energy storage system as a primary source provides low efficiency and a high level of degradation in the storage components, as they use batteries such as the Ni-MH to fix the point of operation of the panel, forcing the batteries to Recharge cycles daily and consequently degrading its life [3]. However technology storage battery is conveyed through an electrochemical process, which produces a reduced battery life-time, requiring constant maintenance, and harmful effects to make charging and discharging in an inappropriately way. But these disadvantages would be insignificant when referring to a technology such as ultracapacitors and superconducting coils.

Ultracapacitors technology has been developed over 50 years ago, the charging and discharging speeds are in the range of seconds, they require no maintenance, are capable of supporting high currents and have a high power density. 
Ultracaps are an emerging device for energy storage with a higher power density than batteries from 10 to 20 times that of regular electrolytic capacitors. They can be charged and discharged continuously without degradation and are ideal for pulsating applications [3]. However, nowadays the technology is still expensive compared with batteries but its advantages at the environmental level are significant. In spite of this, new materials for electrodes in supercapacitors have been studied including graphene and active carbon, achieving devices of smaller size, reducing its cost and increasing the density of energy [4]. Another important factor in these devices is their size: they can be five or more times the size of a battery with the same capacity. This is why this technology has not been popularized. On the other side, superconducting coils are able to inject or absorb large amounts of energy in very short periods of time, being used to solve quality grid problems. Both, Supercapacitors and Superconducting coils have a high renewable potential, but its widespread implementation has not been possible due to their high production costs and its limited distribution in the market.

The different storage devices characteristics raise the question of what storage system is more appropriate for an isolated solar photovoltaic system. Isaac Gil Mera, in his work "Designing a storage system Hybrid based on batteries and supercapacitors for use in electric microgrid" [5] has shown how batteries and ultracapacitors can complement and help each other in different applications, including implementation in small networks due to their contrasting characteristics of energy density and power density. Supercapacitors improve a photovoltaic system based on batteries, extend the life of the batteries and reduce the cost of maintenance [6]. Recent research [7] demonstrates that the integration of supercapacitor packs in the photovoltaic energy storage system conduce to low rates of charge/discharge current of battery and reduces the current stress levels on battery. If it were evaluated only by its environmental effect, the answer to the question posed above would focus on ultracapacitors and superconducting coils, but its features must also be evaluated as essential aspects of operation and longterm durability in the photovoltaic solar system. Therefore, this work tests Liion, $\mathrm{NiMH}$ batteries and a supercapacitor, which were charged by solar panels of the same capacity, in the same environmental conditions, their charge regulation were made through MPPT's regulator, taking tension- time data of the accumulators through a data acquisition board and LabView. The batteries when using a conventional charger are charged at a constant current to prevent internal damage and many of these chargers are often disconnected once they detect that the battery reached full charge. However, when loaded with a photovoltaic generator whose current is proportional to the solar irradiance received, totally different behavior is observed, even in the presence of regulators that help battery to not exceed its limits.

In the plotting curves in MATLAB of this experiment the memory effect in Nickel batteries is clearly seen, where the battery reached a constant value of tension of approximately $76 \%$ of its nominal voltage value, not being able to reach $100 \%$ of its rated voltage and without being able to discharge completely. 
This effect is attributed to frequent non uniform charges in which crystals accumulate inside, preventing the battery of being fully charged. For their part, the Li-ion batteries presented small discharges with a duration of a few minutes at different moments of charging, but this effect did not affect their subsequent behavior. The supercapacitor charging process generates a similar voltage-time curve like the one of a traditional capacitor charged with a conventional source but furthermore presents supercapacitor voltage peaks in instants where irradiance was taking considerable high values.

\section{Photovoltaic Systems}

An isolated solar photovoltaic system is a system that is not connected to the electricity grid, so it should be designed to supply all the energy for the system and should be able to store energy for periods when the solar resource is not abundant. This system usually consists mainly of a photovoltaic generator or panel, a regulator, a battery and a load, as shown in Figure 1. Some have an inverter to convert the direct current into alternating current supplying equipment that work under this type of current. In this paper three isolated solar photovoltaic systems were implemented: with $\mathrm{Li}$-ion, $\mathrm{NiMH}$ batteries and supercapacitor respectively. Photovoltaic generators used in this work were polycrystalline panels of $5 \mathrm{~W}$ each one, connected to regulators MPPT adjusted nominal voltage value of each battery and supercapacitor as shown in Figure 2, where the whole system connection is observed. The Regulator used in this work was the MPPT solar controller Board of 5 amps DC/DC with efficiency up to 95\%. Losses in photovoltaic solar systems are very high, mainly due to the fact that photovoltaic generators have limited efficiencies and do not convert $100 \%$ of the solar irradiance into useful electrical energy, in addition to the losses generated by the wiring and power electronics elements as regulators and inverters.
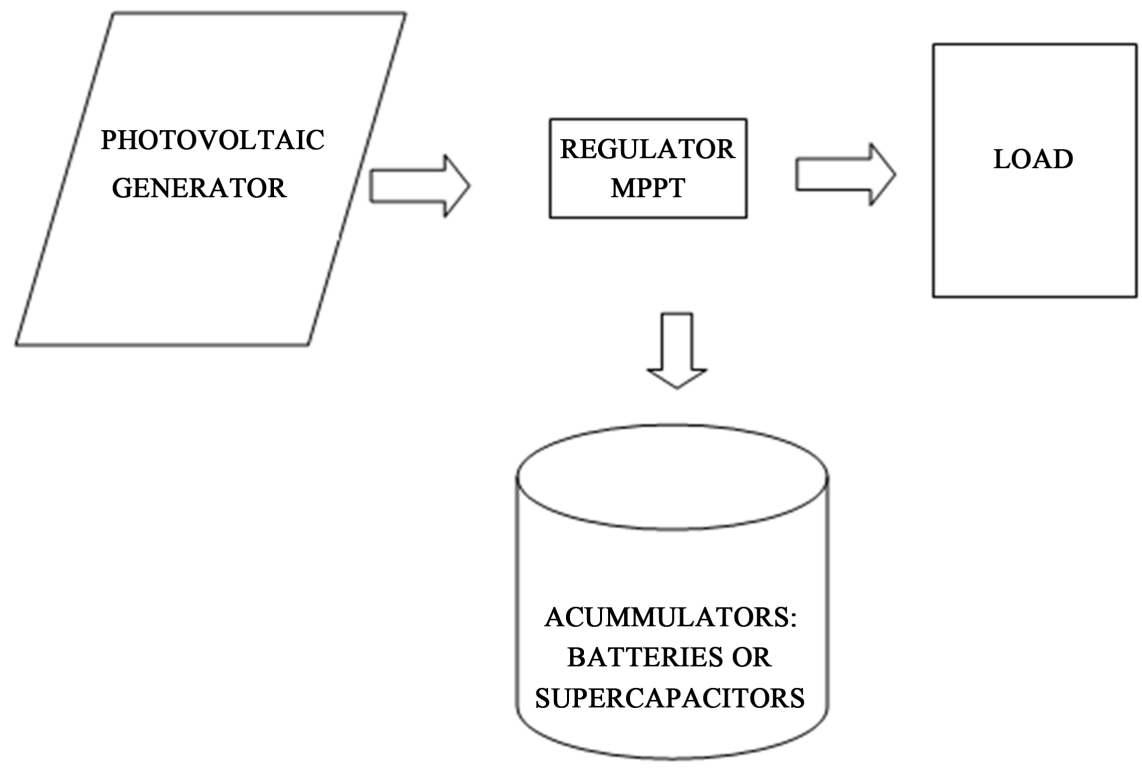

Figure 1. Diagram of a photovoltaic solar system isolated. 


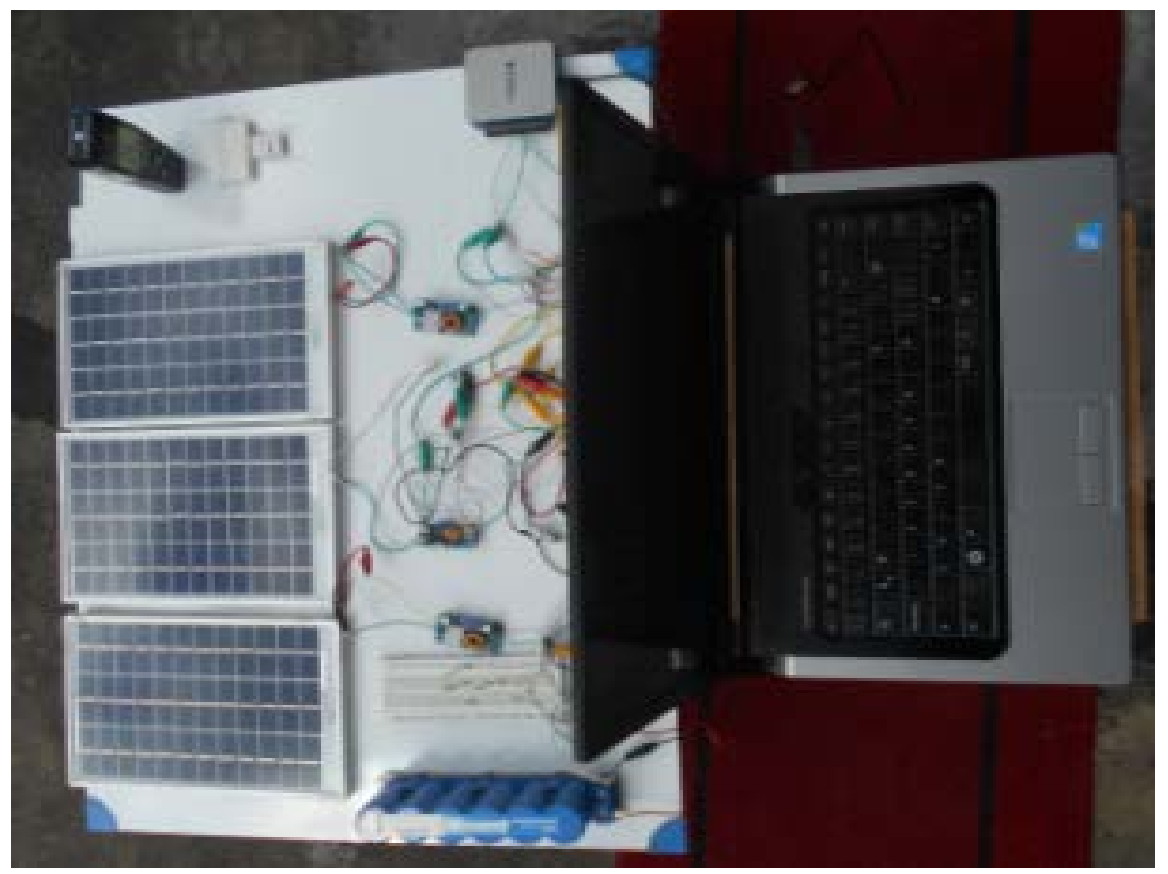

Figure 2. Connection of solar photovoltaic system with the data acquisition system. This Figure shows the real connection scheme of photovoltaic system: panels, regulator, batteries and the supercapacitor including the USB-6000 National Instruments board.

\section{Accummulators Used in Photovoltaic Solar Systems}

The storage system of an isolated solar photovoltaic system must be designed to store more energy and thus ensure that the system has a couple or more of days of autonomy and to have a regulator that fits the voltage values, avoiding high current that the battery cannot support and thereby preventing further damage. Accumulation systems used in this work were the nickel-metal hydride, lithium ion and a supercapacitor each with about the same capacity energy storage as shown in Table 1.

There are different types of supercapacitors however the main ones are the double layer electrochemical capacitors, pseudocapacitors or redox capacitors. A supercapacitor consists of three main components: a current collector, active materials (electrodes) and a separator. Interfaces between electrodes and electrolytes store energy in EDLCs, allowing capacitors to deliver high power and ensure exceptional cycle life. The energy density of the EDLCs depends on two factors: the capacity of speculation and the operating voltage [2]. The ultracap used in this work is 58 Farads and 16 Volts, the Figure 3 and Figure 4 show the curves provided by manufacturer.

Three batteries in each of the configurations were arranged in series with the purpose of incrementing tension without affecting its capacity. There are multiple methods for determining the state of charge (SOC) of a battery, among them are tension method, electrolyte density method and the spectroscopic impedance, but some of these methods cannot be carried out if the battery is connected in a photovoltaic system. In his research about solar photovoltaic systems [8] Miguel Alonso Abella discuss that due to the difficulty in determining the 
ESR AND CAPACITANCE VS TEMPERATURE

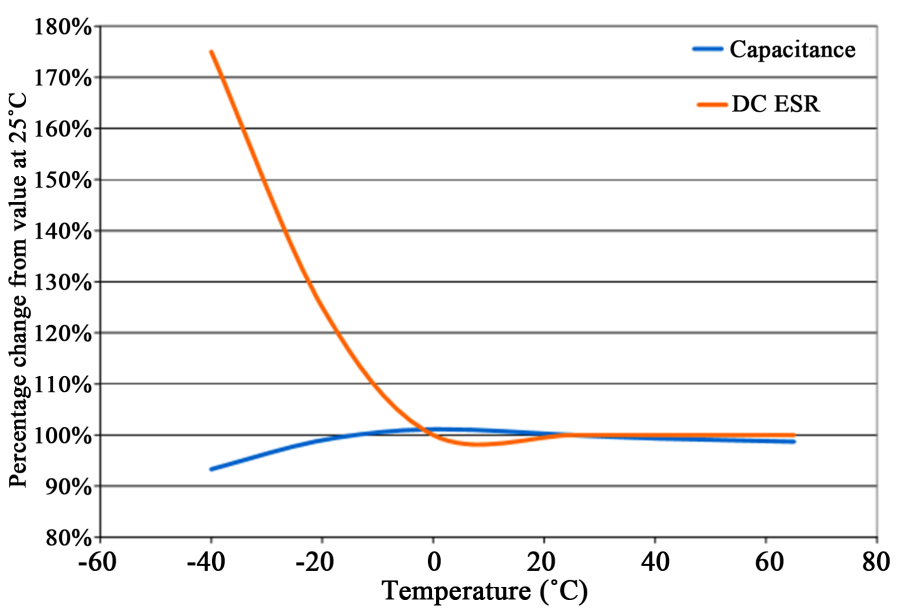

Figure 3. Ultracap Curve of Equivalent Resistance Series (ESR) and Capacitance Vs Temperature provided by the Maxwell manufacturer.

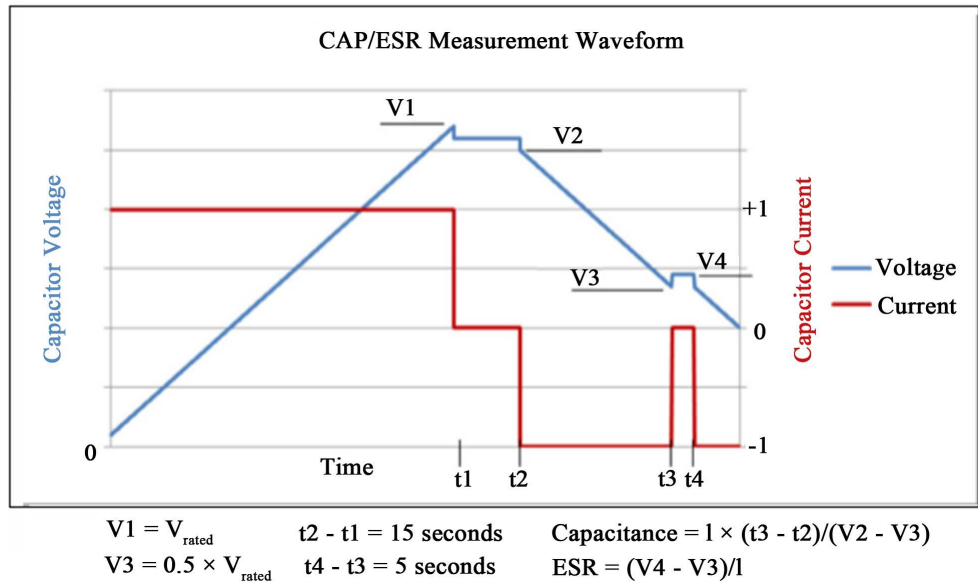

Figure 4. Ultracap measurement waveform current and voltage provided by Maxwell manufacturer.

Table 1. Characteristics of accumulators.

\begin{tabular}{|c|c|c|c|c|}
\hline$\#$ & Accumulators & Basic characteristics & Apperance & Price (US dolars) \\
\hline 3 & $\mathrm{NiMH}$ & $\begin{array}{l}\text { Nominal voltage: } 3.6 \mathrm{~V} \\
\text { Capacity: } 600 \mathrm{mAh} \\
\text { Stored Energy: } 2.1 \mathrm{Wh}\end{array}$ & 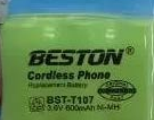 & 6 \\
\hline 3 & Li-Ión & $\begin{array}{l}\text { Nominal voltage: } 3.6 \mathrm{~V} \\
\text { Capacity: } 690 \mathrm{mAh} \\
\text { Stored Energy: } 2.5 \mathrm{Wh}\end{array}$ & & 12 \\
\hline 1 & Ultracapacitor & $\begin{array}{c}\text { Rated voltage: } 16 \mathrm{~V} \\
\text { Capacitance: } 58 \mathrm{~F} \\
\text { Stored Energy: } 2.1 \mathrm{Wh}\end{array}$ & & 123 \\
\hline
\end{tabular}


state of charge of the batteries, the method of measurement of voltage in its terminals has been raised. In this method voltage when the battery is being charged, the voltage rises respect to open circuit voltage (VOC) and when it discharge, voltage decreases. Accordingly, it would be expected to measure the voltage at the battery knowing the state of its charge. The time of discharge of the batteries can be calculated with the next equation, where corresponding to discharge time in hours; is the capacity of the battery in Amp/hour, and is the discharge current in Amp.

$$
t=C / I
$$

For their part supercapacitors although are more robust devices have many advantages not only in terms of being friendly to the environment but also in terms of functionality. According Menendez Diaz, in his book "Coal in everyday life", "the main virtue of ultracapacitors is the power that is able to develop, also accumulating amounts considerable energy, which added to its fast charging and discharging, and a large cyclability, make it an optimal device for use in different storage systems" [9]. The charge and discharge of supercapacitors can be compared with a traditional capacitor. The supercapacitor discharge voltage can be calculated from the equation

$$
V(t)=\frac{Q}{C} * \mathrm{e}^{-\frac{t}{R C}}
$$

In this work the discharge was made through constant loads of 22, 27 and 49 ohms, which allows fast downloads, in the table below the expected discharge times battery and Supercapacitor is observed in Table 2.

Each accumulator tension-time data were extracted through a board data USB-6000 National Instruments and DAQ Assistant via LabView as seen in Figure 5, which exported data voltage battery and supercapacitor information to Excel. Due operating ranges of the USB-6000 National Instruments board was necessary to make a resistive divider to reduce the nominal voltage of the supercapacitor to a value that fits the range of the card, in this case $10 \mathrm{~V}$. The radiance data were taken consecutively through solar power meter ES-2000.

Figures 6-25 provides graphics of solar irradiance, charging and discharging. The red line represents the supercapacitor and blue and green ones $\mathrm{Ni}-\mathrm{MH}$ and Li-ion respectively. In the graphics of irradiance the blue line corresponds to the first charge and the green and red lines describe the second and third charge respectively, if exists.

Table 2. Discharge times of the batteries and supercapacitors in hours.

\begin{tabular}{cccc}
\hline Accumultor/Loads & $\begin{array}{c}\text { First Load } \\
(22 \mathrm{ohms})\end{array}$ & $\begin{array}{c}\text { Second Load } \\
(27 \mathrm{ohms})\end{array}$ & $\begin{array}{c}\text { Third Load } \\
(49 \mathrm{ohm})\end{array}$ \\
\hline Nickel Metal Hydride Battery & 1.36 & 1.65 & 2.9 \\
Lithium Ion Battery & 1.56 & 1.86 & 3.38 \\
Ultracap & 1.77 & 2.17 & 3.94 \\
\hline
\end{tabular}




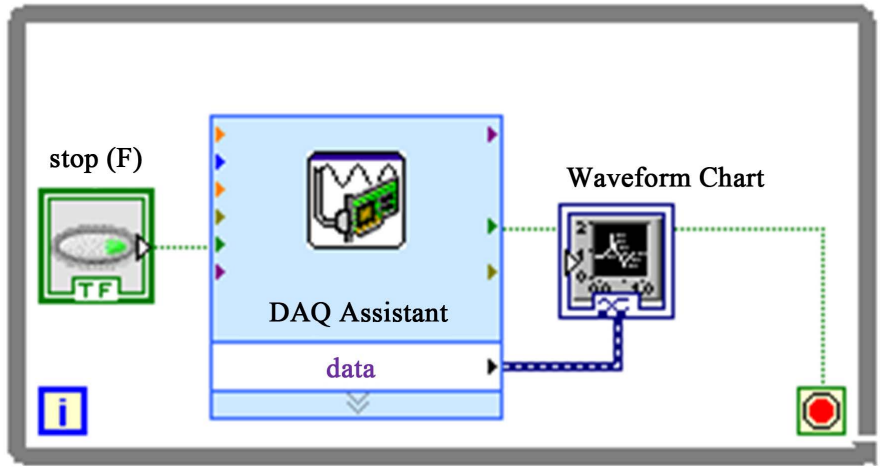

Figure 5. LabView scheme for connection with the DAQ assistant.

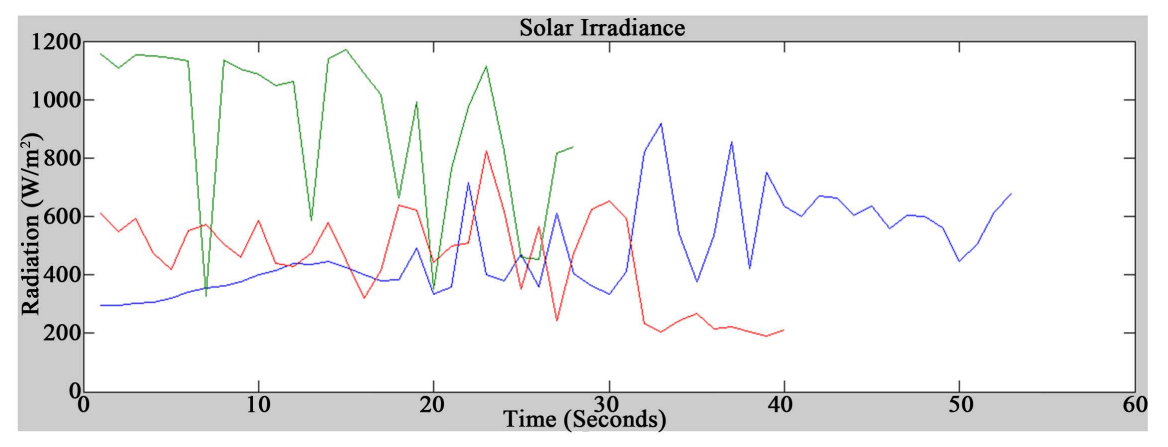

Figure 6. Solar Irradiance-time curve day 1.

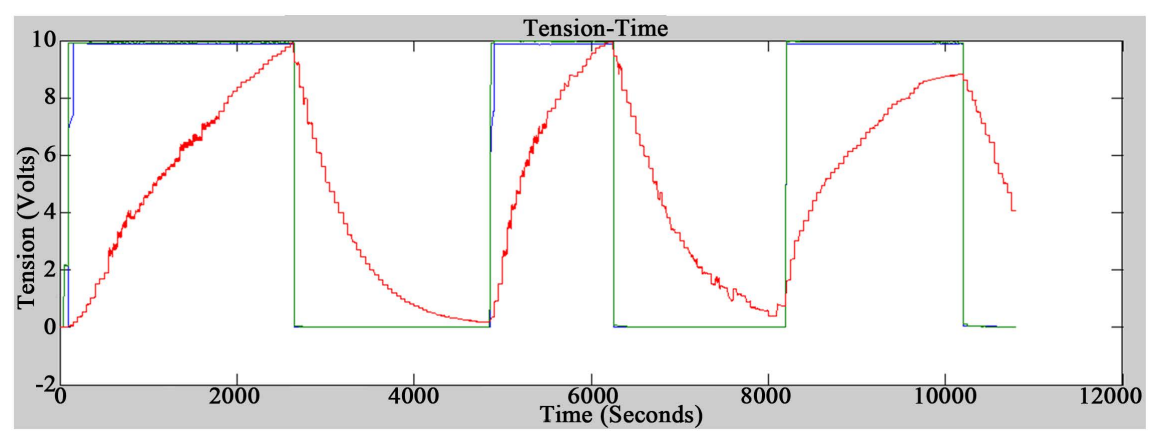

Figure 7. Curve tension-time day 1.

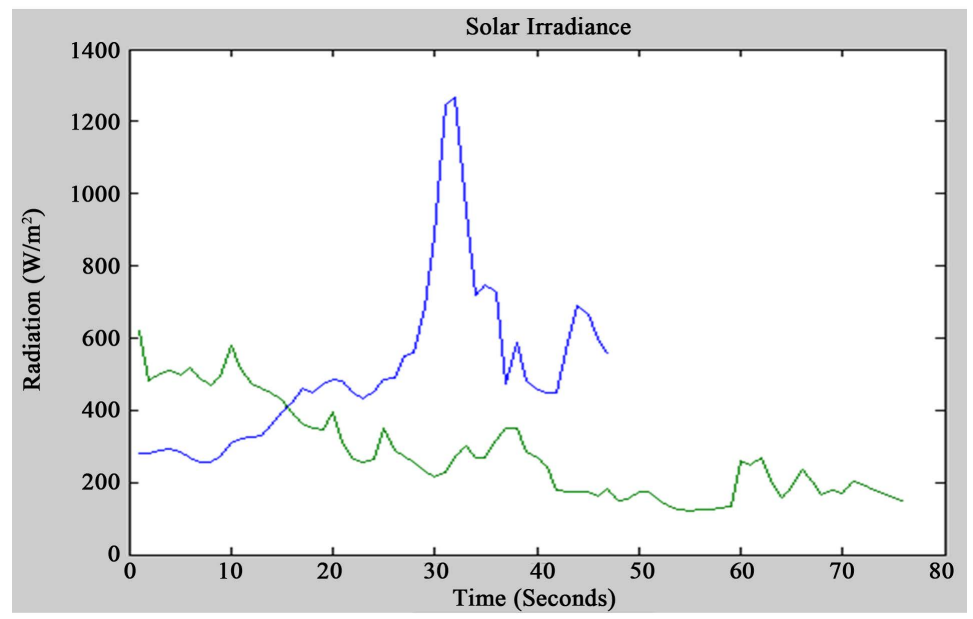

Figure 8. Solar Irradiance-time curve day 2. 


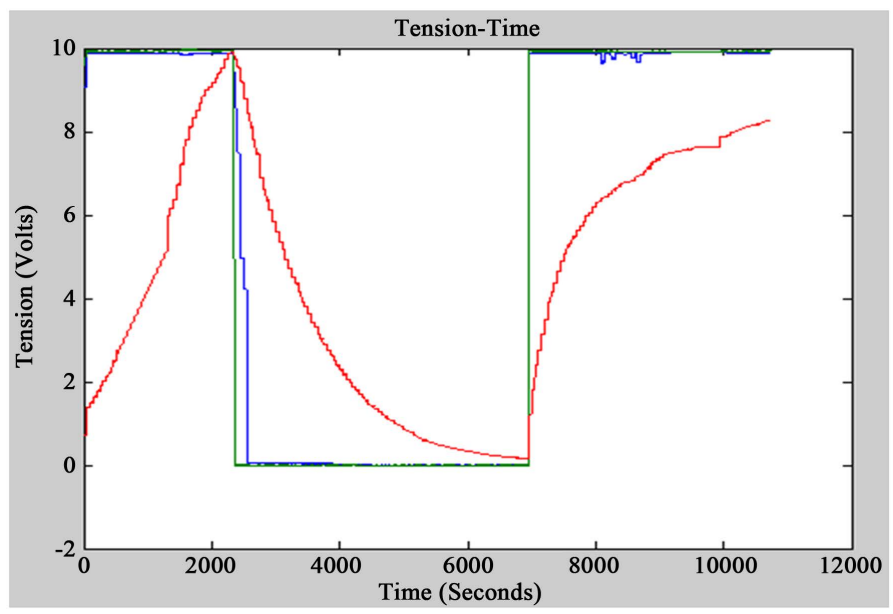

Figure 9. Curve tension-time day 2.

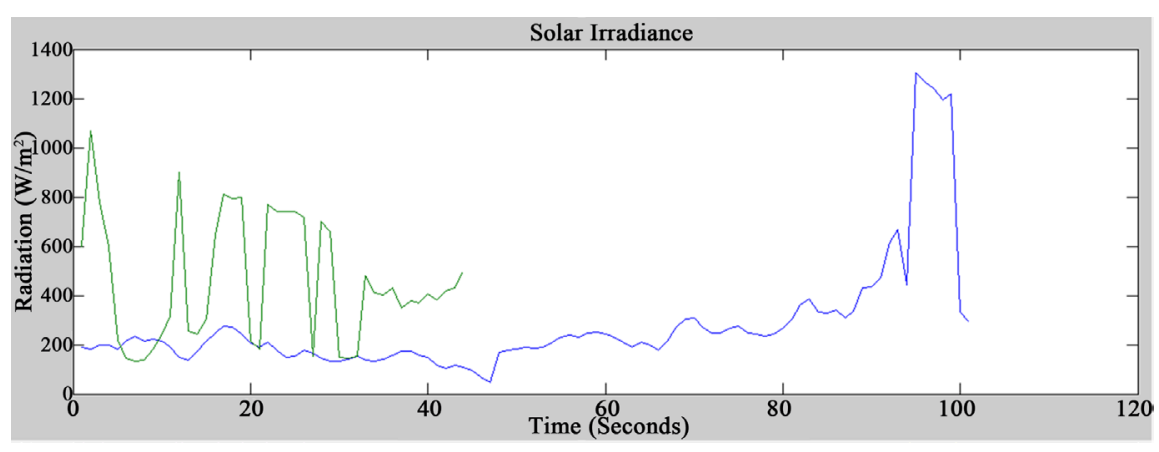

Figure 10. Solar Irradiance-time curve day 3.

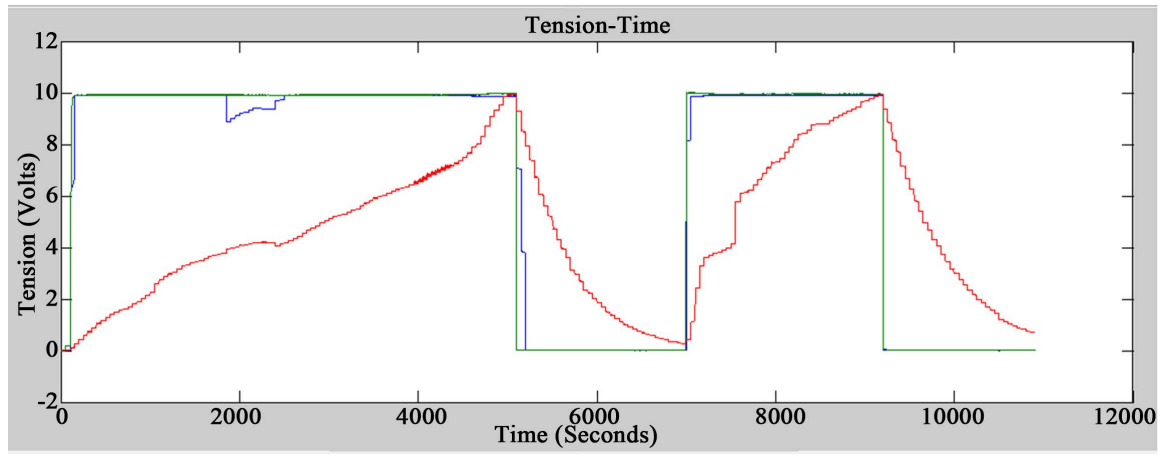

Figure 11. Curve tension-time day 3.

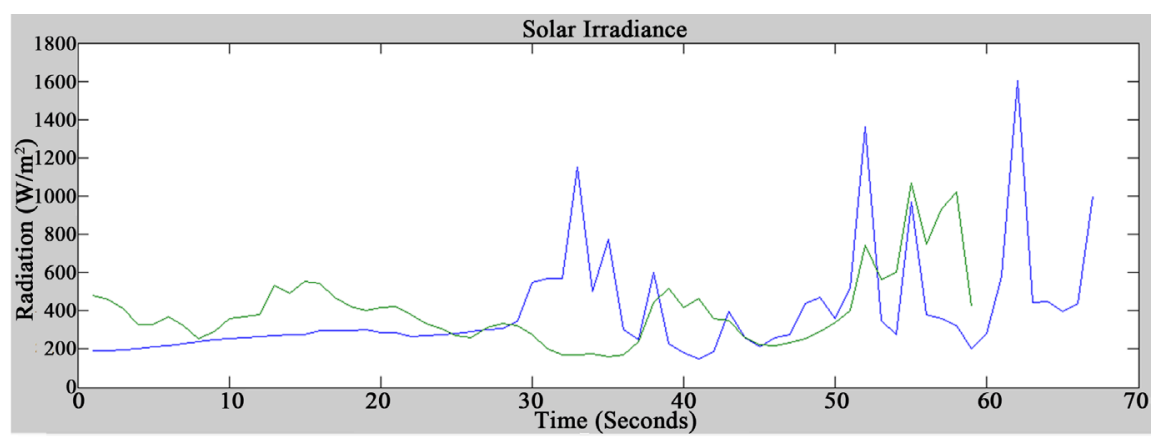

Figure 12. Solar Irradiance-time curve day 4. 


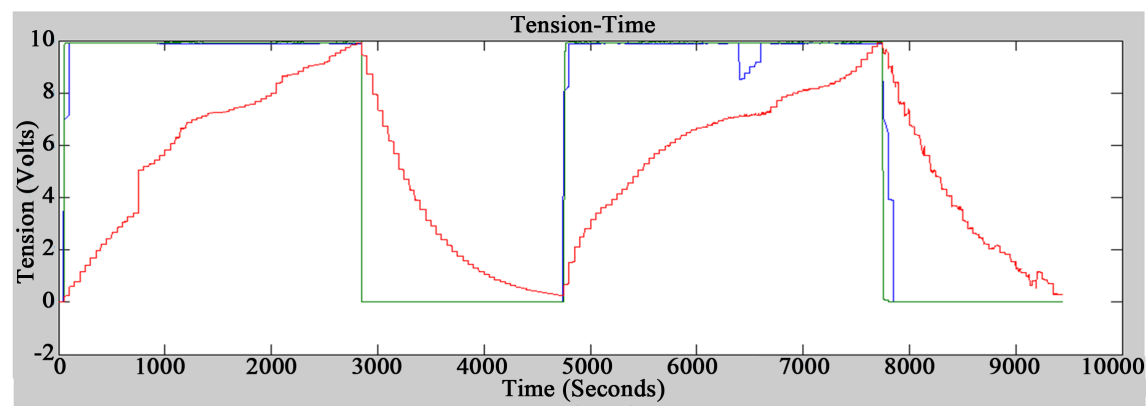

Figure 13. Curve tension-time day 4.

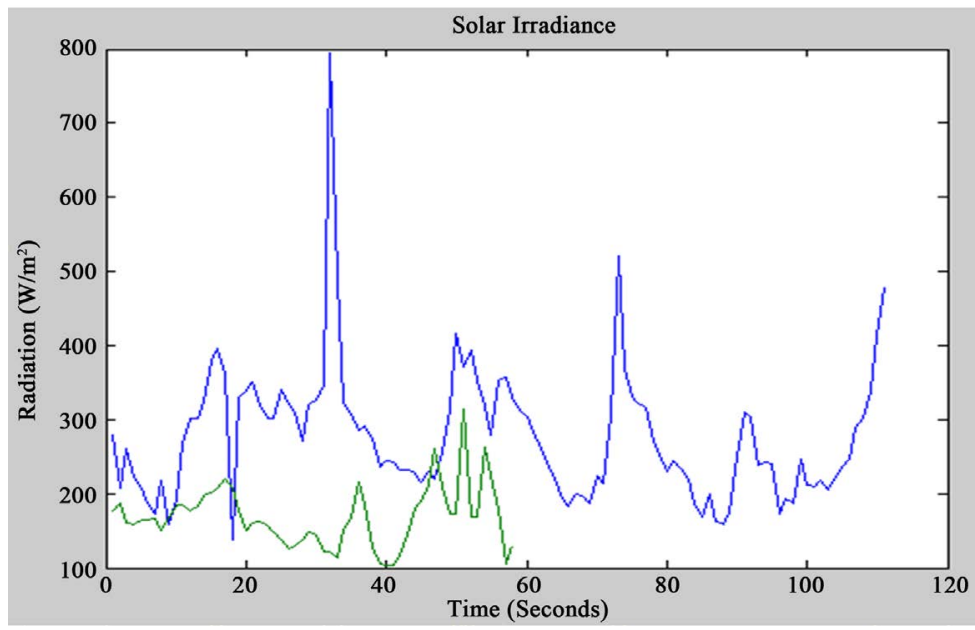

Figure 14. Solar Irradiance-time curve day 5.

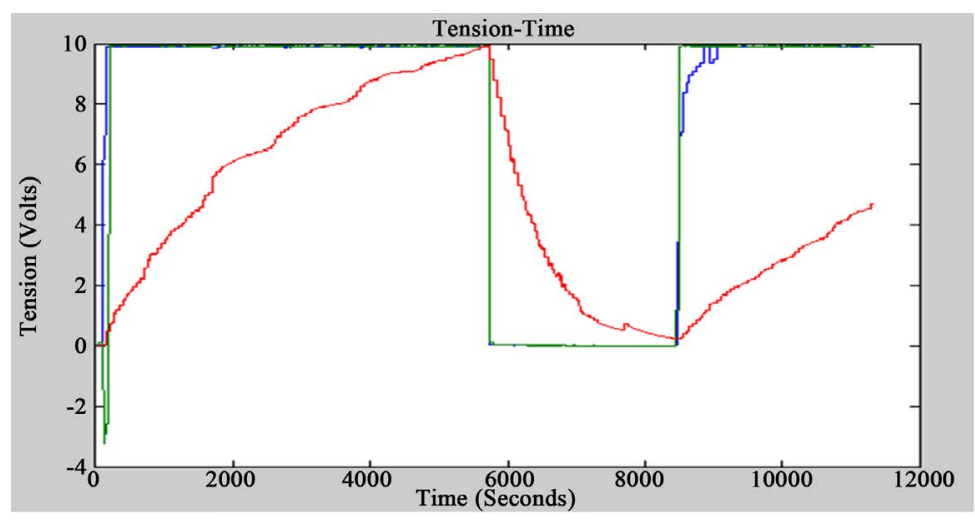

Figure 15. Curve tension-time day 5.

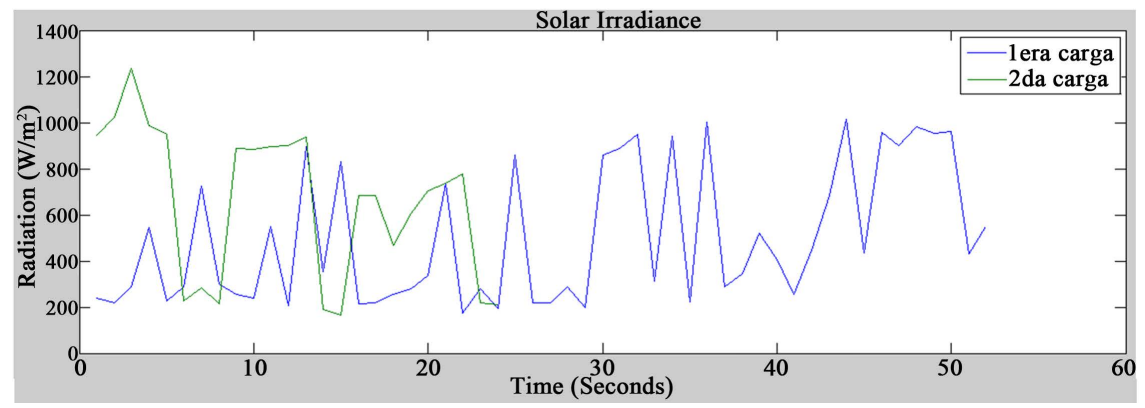

Figure 16. Solar Irradiance-time curve day 6. 


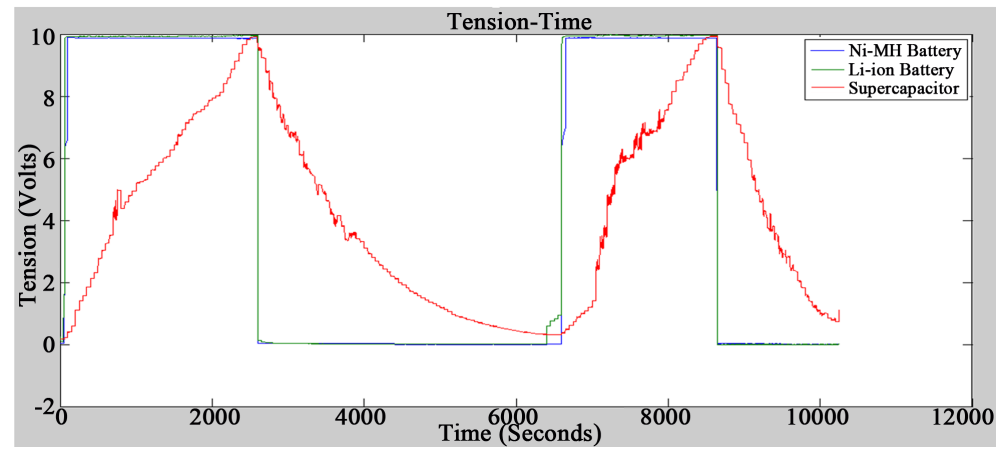

Figure 17. Curve tension-time day 6.

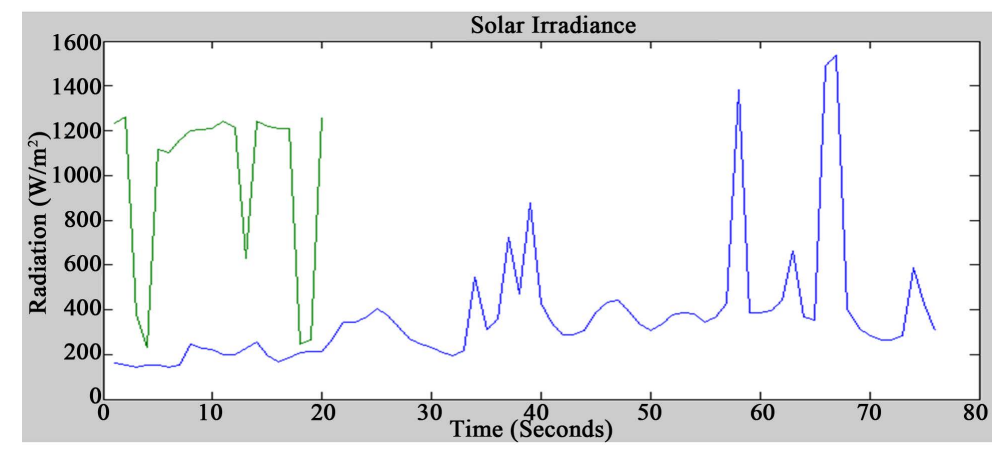

Figure 18. Solar Irradiance-time curve day 7.

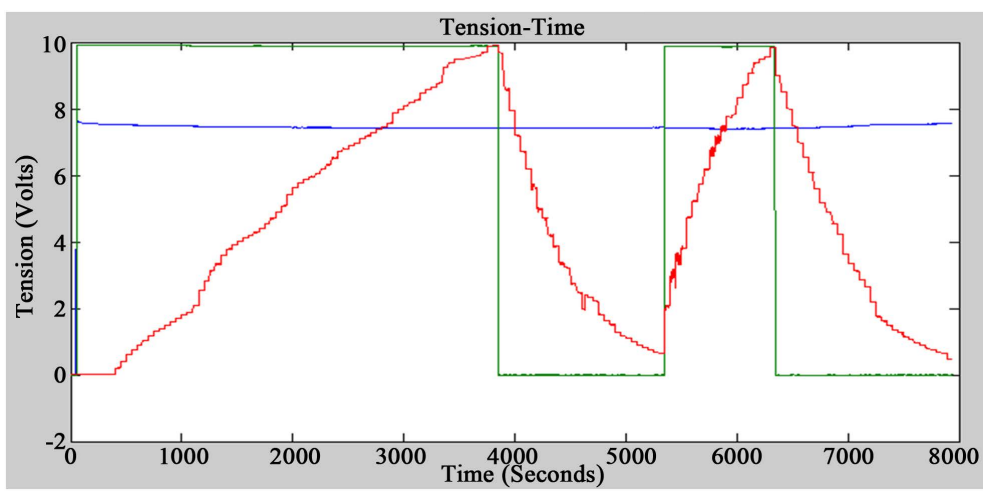

Figure 19. Curve tension-time day 7.

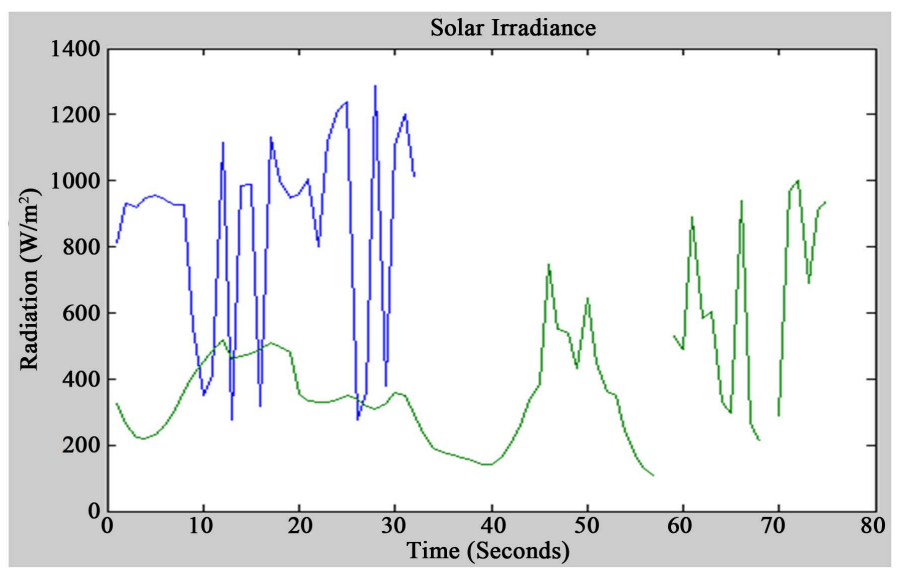

Figure 20. Solar Irradiance-time curve day 8. 


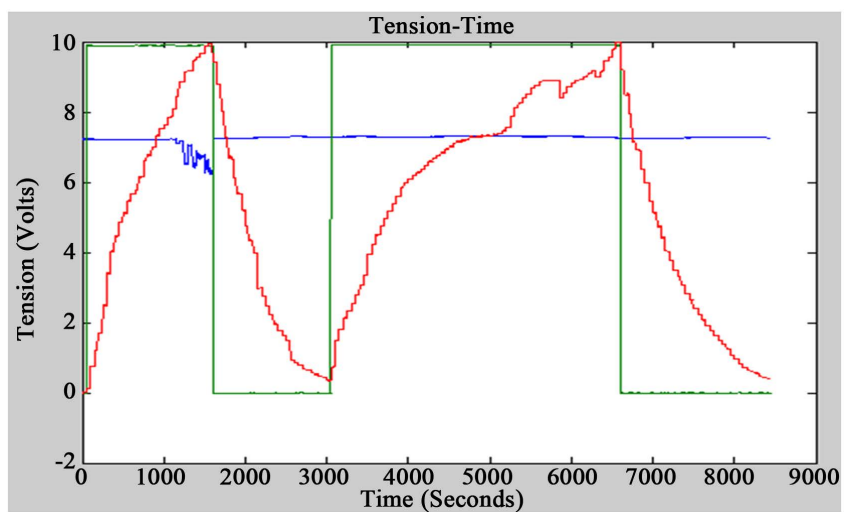

Figure 21. Curve tension-time day 8.

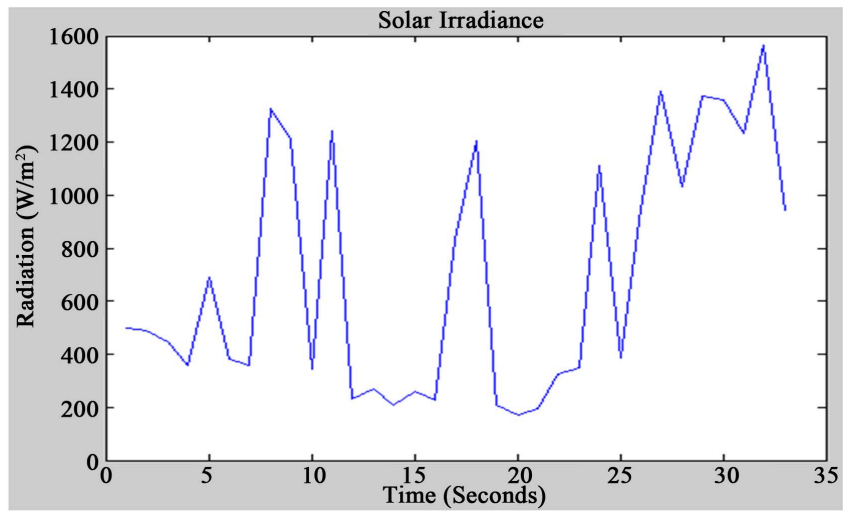

Figure 22. Solar Irradiance-time curve day 9.

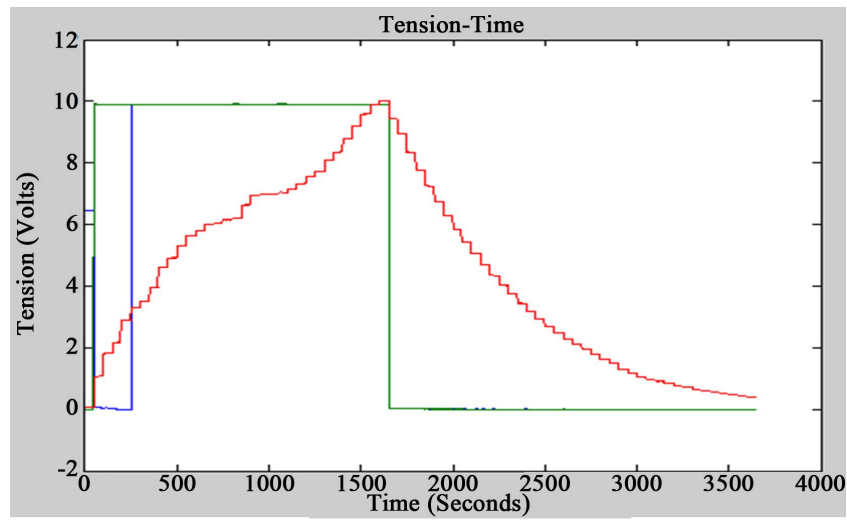

Figure 23. Curve tension-time day 9.

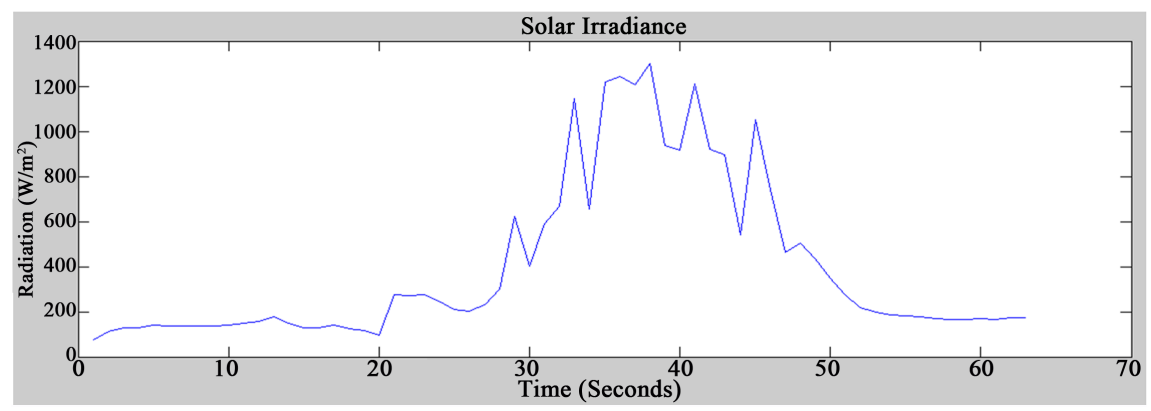

Figure 24. Solar Irradiance-time curve day 10. 


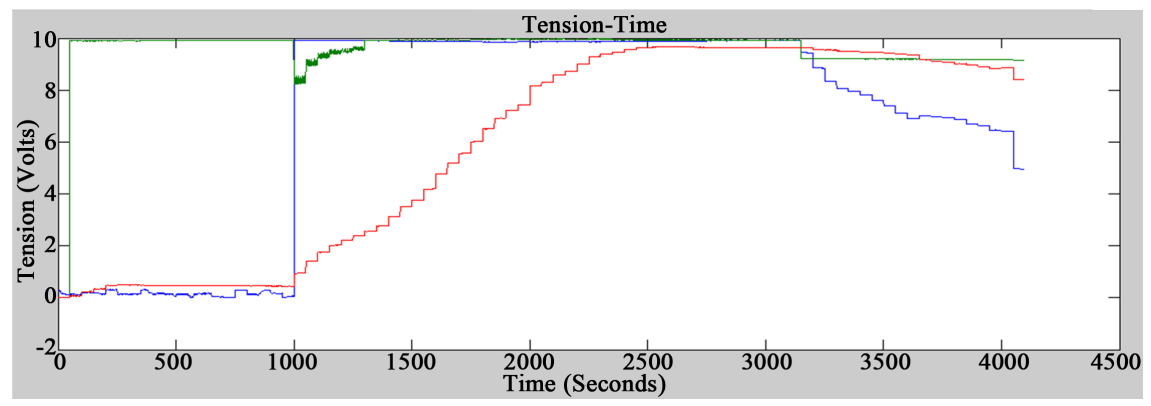

Figure 25. Curve tension-time day 10.

In Figure 11 and Figure 13, respectively, the process of partial discharge in the nickel battery can be appreciated, whereby the battery is discharged for a few seconds, recovering its voltage value before discharge. This effect reaches a 19\% reduction of its rated voltage. The reaction of the nickel battery in Figure 19 and Figure 21 respectively is known as memory effect, which is characterized by the temporary loss of the battery discharge capacity. In this particular case the voltage reached $76 \%$ nominal value recovering its capacity after 4 cycles, as shown in Figure 23 and Figure 25 respectively. Figure 19 shows the appearance of two simultaneous effects: the memory effect and partial discharge effect, which appears for 6 minutes, and disappears the next day in the battery Nickel Metal Hydride. In the other hand, the lithium battery even when having the same number of cycles than the Nickel Hydride battery, doesn't present memory effect as expected. However on day 10 as shown in Figure 25, the lithium ion battery presents a partial discharge, recovering a few minutes later.

The scale factor of time in the Voltage-Time curve is 1: 2 seconds, in order to appreciate that the supercapacitor charges vary within a range of 25 minutes to 90 minutes, depending on the current generated by the panel. It should be noted that not every day more than one charge could be obtained due to weather conditions and irradiance that often was so low that provided very long charge in the supercapacitor. In Figure 15 a voltage peak in the supercapacitor first charge the can be observed, and repeated voltage peaks in the second supercapacitor charge the even supercapacitor has not presented memory effect, or partial discharging during charge, additionally these voltage peaks did not generated effects on their subsequent behavior.

\section{Data Acquisition System}

The device used for data acquisition in this work was the DAQ 6000 NI. This device is multifunctional and provides basic functionality for different applications. It offers analog/ digital inputs and outputs and 32 bit counter.DAQ device has the characteristics mentioned in Table 3 . The supercapacitor voltage is $16 \mathrm{~V}$, and DAQ 6000 board has an operating range of -10 to +10 , due this was necessary a resistive divider at the output of the supercapacitor.

\section{Error Analysis}

Although there are several possible causes of error, such as: error due to instru- 
Table 3. Characteristics of analog input in DAQ 6000.

\begin{tabular}{cc}
\hline Number of Analog Inputs & 8 single-ended \\
Input Resolution & $12 \mathrm{bits}$ \\
Maximum Sample Rate & $10 \mathrm{KS} / \mathrm{s}$ \\
Converter Type & Successive approximation \\
AI FIFO & 2047 samples \\
Timming Resolution & $125 \mathrm{~ns}$ \\
Timming Accurracy & $100 \mathrm{ppm}$ \\
Input range & $\pm 10 \mathrm{~V}$ \\
Working Voltage & $\pm 10 \mathrm{~V}$ \\
Input Impedance & $>1 \mathrm{M} \Omega$ \\
Overvoltage Protection & $\pm 30 \mathrm{~V}$ \\
System Noise & $10 \mathrm{mVrms}$ \\
\hline
\end{tabular}

ment measuring, error due to the operator, error due to environmental factors, errors due to the geometry of the devices, among many others. Here it will assume that the maximum error is the instrumental error, in this particular case the instrumental error is due to the data acquisition board DAQ $6000 \mathrm{NI}$ which was the instrument by means of which the data were extracted. It is necessary to know that the main contributors to the error in a system of analog data acquisition inputs are Offset Error, Gain Error, Integral Non-Linearity Error and Noise [10]. Maximum Error is calculated by the following Equation (3):

Max Error = Input offset + Gain Error + Integral Non Linearity Error + Noise

Using Equation (3) with the values found in the manufacturer specifications of the data acquisition board in Table 3, the error calculated was 0,05832368 . Therefore, it could be concluded that the data have an error margin of 5.83\% with respect to its real value.

\section{Discussion}

Although authors ascribe the memory effect only to Ni-Cd batteries, this effect is also present in Ni-MH batteries in a relatively small percentage, albeit it is a temporary effect, it reduces the battery life, however it is reversible through the application of complete cycles of charge-discharge as mentioned by Viera Perez in his work "fast battery charging Ni-Cd and Ni-MH, medium and large capacity, synthesis and comparison of new methods" [11] in which he argues that "the temporary loss of capacity can be recovered fully after applying two complete cycles of charge-discharge consecutively". This statement can be corroborated in the present work. Despite charge control in photovoltaic systems is done by regulators, that measure the voltage and protect the battery, in this work, the value of the battery voltage does not correspond to the state of charge of the battery generating partial loads, producing memory effect as stated by Martinez Garcia and Gualda Gil in their book "Electronic components power topologies and 
equipment" [12], "memory effect is the result of successive cycles of partial loads, in which grouped granules of active material offering less surface contact with the electrolyte", causing that the battery do not reach full charge. Another relevant factor in implementing solar photovoltaic systems is the correct calibration of the voltage regulator, since a misadjusted or damaged regulator may affect measurements and battery life causing overload, over-discharge and even the above-mentioned memory effect.

Being the irradiation a variable factor, which is presented in photovoltaic solar systems, storage devices typically do not have full charges, or may present a series of mixtures between fast and slow charges during different periods of time in the same cycle. This factor affects batteries notoriously, generating harmful effects to them and reducing its life, in contrast, the supercapacitor doesn't appear to be affected by abrupt changes. Supercapacitors, when receiving more current reduce charging times. Although ultracapacitors are one of the most expensive storage devices, it is easy to adjust the behavior of a solar photovoltaic system, due to the high currents that can it support, their satisfactory behavior against incomplete deep charging and discharging, that can notably affect the batteries, but in the case of supercapacitor it can be supported without producing health problems, presented daily related to the use of photovoltaic solar systems. In addition, ultracapacitors would be appropriate for photovoltaic installations where consumption increase with time, as they have high power density, which allows high currents to dissipate quickly. Eventually, when using supercapacitors, regulators functionality is limited, since lesscomplex regulatory circuits would be required in order to avoid deep discharge and therefore making them less expensive. Supercapacitors are known for their fast charges and discharges compared to batteries, however as can be seen in Table 2, the charge times on the capacitor is longer than the charge in the battery, this is due to the high capacitance of the supercapacitor that increases the time constant, being for the battery, discharge depending directly of the current, in this case the accumulators has a small storage energy capacity of $2.1 \mathrm{Wh}$, but for high values of storage energy ,the supercapacitor present times of charge faster than batteries as it is possible to calculate for $21 \mathrm{Wh}$.

\section{Conclusion}

Continuous charging and discharging non uniform cycles markedly deteriorate the life of the battery; effects such as memory can be reversible after some continuous charge and discharge cycles despite the deterioration in the internal components of the battery is a progressive process. A important factor in the implementation of batteries in photovoltaic solar systems is also the correct calibration of the regulators In this process the battery can suffer overvoltage that affect its useful life, however this is not a problem for the supercapacitor that is designed to receive overvoltage and high currents, In this work the supercapacitors show a waveform as expected from the provided curves of the manufacturer, although for this example of a Low-power solar system the supercapacitor does not have short charging and discharging times, its performance and health 
characteristics after continuous charging and discharging cycles are the same that at the start of the experiment. Ultracaps have a longer life compared to the batteries; in addition to its internal components has less deterioration than the battery and it doesn't present memory effect, no need regulators or maintenance and according to the temperature curve of the manufacturer the capacitance is kept almost constant with the increase of the temperature which means that the high temperature does not affect the behavior of the supercapacitors. For all of that, the supercapacitor is being a better long-term alternative in a solar photovoltaic system.

\section{Acknowledgements}

A special thanks to the district University Francisco José de Caldas, who made possible this research.

\section{References}

[1] Michael, F.M. and Henderson, C. (2002) Recycling Batteries. IEEE, 35, 36.

[2] Zhao, Z., Richardson, G., Meng, Q., Zhu, S. and Kuan, H. (2015) PEDOT-Based Composites as Electrode Materials for Supecapacitors. IOP Publishing Ltd, Bristol.

[3] da Cunha, A. and Silva, D. (2010) Energy-Efficient Characterization of Solar Panel-Supercapacitors System for Energy-Harversting Aware Wireless Sensor Nodes. IEEE 20 th International Symposium, 2276.

[4] Li, S., Wang, X., Xing, H. and Shen, C. (2013) Micro Supercapacitors Based on a 3D Structure with Symmetric Graphene or Actived Carbon Electrodes. Journal of Micromechanics and Microengineering, 23, 9.

[5] Gil, I. (2012) Diseño de un sistema de AlmacenamientoHíbridobasado en baterías y Supercondensadoresparasuuso en microredeléctrica. Universidad de Sevilla, Sevilla España.

http://bibing.us.es/proyectos/abreproy/4740/fichero/3.+Sistema+de+almacenamient o+hibrido.pdf

[6] Fahmi, M., Rajkumar, R., Arelhi, R. and Isa, D. (2015) Study on the Effect of Supercapacitors in Solar PV System for Rural Application in Malaysia. Power Engineer Conference (UPEC), UK, December 2015, 4.

[7] Cabrane, Z., Ouassaid, M. and Maaroufi, M. (2015) Performance Analysis of Supercapacitors Integration in Photovoltaics Energy Storage Systems. Renewable and Sustainable Energy Conference (IRSEC), 2015.

[8] Abella, M. Sistemassolaresfotovoltaicos. Centro de investigaciones Energéticas, Medioambientales y tecnológicas. http://api.eoi.es/api_v1_dev.php/fedora/asset/eoi:45337/componente45335.pdf

[9] Menéndez, J. (2012) El carbón en la vidacotidiana: De la pinturarupestre al ascensorespacial. CreateSpace Independent Publishing Platform, USA, 108.

[10] Judd, B. (2016) Everything You Ever Wanted to Know about Data Adcquisition. United Electronic Industries, Walpole, Massachusetts.

[11] Viera, J. (2003) Cargarápida de Baterías de Ni-Cd y Ni-MH, de media y gran capacidad, síntesis y comparación de nuevosmétodos. Universidad de Oviedo, España.http://www.tdx.cat/bitstream/handle/10803/11142/UOV0036TJCVP.pdf

[12] Martínez, S. and Gualda, J. (2006) Electrónica de potenciacomponentes, topologías y equipos. Thompson ediciones, Madrid España. 
Submit or recommend next manuscript to SCIRP and we will provide best service for you:

Accepting pre-submission inquiries through Email, Facebook, LinkedIn, Twitter, etc. A wide selection of journals (inclusive of 9 subjects, more than 200 journals)

Providing 24-hour high-quality service

User-friendly online submission system

Fair and swift peer-review system

Efficient typesetting and proofreading procedure

Display of the result of downloads and visits, as well as the number of cited articles Maximum dissemination of your research work

Submit your manuscript at: http://papersubmission.scirp.org/

Or contact epe@scirp.org 